\title{
Determination of Physicochemical Properties and Fatty Acid Composition of Kabate Larva Oil from Timor Island
}

\author{
FEBRI ODEL NITBANI ${ }^{1 *}$, HERMANIA EM WOGO ${ }^{1}$, , TITUS LAPAILAKA ${ }^{1}$ \\ and BETA ACHROMI NUROHMAH ${ }^{2}$
}

\author{
${ }^{1}$ Department of Chemistry, Faculty of Science and Engineering, \\ Universitas Nusa Cendana, Kupang, Indonesia. \\ ${ }^{2}$ Department of Chemistry, Faculty of Mathematics and Natural Sciences, \\ Universitas Gadjah Mada, Yogyakarta, Indonesia. \\ *Corresponding author E-mail: febri_nitbani@yahoo.com
}

http://dx.doi.org/10.13005/ojc/3402058

(Received: September 16, 2017; Accepted: January 15, 2018)

\section{ABSTRACT}

Kabate larva oils could be produced from its larva through soxhlet extraction using $\mathrm{n}$-hexane. Kabate larva, which locally in Timor Island called, can be found in the wounded stem of Sesbania gradiflora L. tree. In this work, the physicochemical properties and the fatty acid composition of Kabate larva oils were evaluated. Kabate larva oils was afforded as viscous yellow liquid with acid value, saponification value, peroxide number, iodine number, kinematic viscosity $\left(\right.$ at $100{ }^{\circ} \mathrm{C}$ ) and specific gravity $\left(15^{\circ} \mathrm{C}\right.$ ) properties were $1.58 \mathrm{mg} \mathrm{KOH} / \mathrm{g} ; 111.28 \mathrm{mg} \mathrm{KOH} / \mathrm{g}$; $2.1554 \mathrm{meg} / \mathrm{kg} ; 44.1426 ; 0.8159 \mathrm{~g} / \mathrm{mL} ; 40.57 \mathrm{~mm}^{2} / \mathrm{s}$ respectively. Based on the GC-MS analysis, it has been found out that fatty acids composition in Kabate larva oil were identified as a palmitic and oleic acid with a percentage value of 43.57 and $56.43 \%$ respectively.

Keywords: Kabate larva oil, physicochemical properties, fatty acid.

\section{INTRODUCTION}

Indonesia is one of the world's top biodiversity rich countries in both flora and fauna. Since ancient times, many ethnic groups of Indonesian traditional societies have used natural products for medical purposes. The facts show that the people of Timor Island traditionally still uses oil from Kabate larva to treat baby's mouth infectious or oral thrush, which is caused by Candida albicans fungus. Oral thrush, or its locally called Gomak disease, is the appearance of thick white layers in the mouth and throat of infants that if it is not handled properly can cause to death. The Kabate larva, in a local language of Timor Island called, is a larva that can be found in the wounded stem of the Sesbania gradiflora L. tree as shown in Figures 1. 


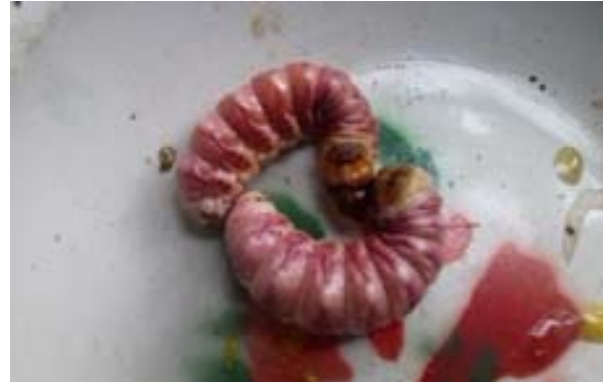

Fig. 1. Kabate larva from Sesbania grandiflora $L$. tree

A review has reported that antimicrobial activity, as well as anti-fungal of the vegetable oils or animal fats, were not lead to by their triglyceride compositions but their monoacylglycerol (monoglyceride) of their fatty acids ${ }^{1}$. Some examples of monoacylglycerol from fatty acids that reported for having antimicrobial activity i.e. monolaurin from coconut oil ${ }^{2,3,4,5,6,7,8}$, monocaprin from coconut oil ${ }^{9}$, monomyristin and monolinolein ${ }^{10}$ and also monoolein ${ }^{11}$.

The facts that are how Timorese traditionally using Kabate larva oil for a treatment of oral thrush in the baby's mouth indicates that its oils have an activity as antifungal against Candida albicans. It has been proposed that the Kabate larva oil has been converted into monoacylglycerol compounds in baby's mouth so it has antifungal activity. However, until now there is no literature have been published regarding the composition of fatty acids and monoacylglycerol in Kabate larva oil. Therefore, this work will be carried out to isolate and determine of some physicochemical of Kabate larva oil. It will be also determined the type of fatty acids in the Kabate larva oil by Gas Chromatography-Mass Spectroscopy.

\section{EXPERIMENTAL METHODS}

\section{Materials}

Materials used in this work were Kabate larva oil, sodium sulfate anhydrous, sodium thiosulfate, hydrochloric acid, glacial acetic acid, starch, potassium iodide, iodine-bromide reagent, phenolphthalein indicator, n-hexane, ethanol, chloroform, and distilled water. All of the reagents were pro analysis grade and purchased from Merck except distilled water and Kabate larva oil.

\section{Instruments}

The instruments used in this study were glass equipment, Soxhlet extractor, and reflux apparatus set. Determination of fatty acid composition was carried out using Gas Chromatography-Mass Spectrometer (GC-MS, Shimadzu QP-2010).

\section{Experimental Procedures Isolation of Kabate larva oil}

Kabate larva were prepared first by peeling the outer skin and its black dirt on the tail. The cleaned Kabate larva (100 g) was then wrapped in a filter paper which in both of the tops and bottom end was put on fatty free cotton. Put the wrapped Kabate larva in a Soxhlet extractor and added nhexane to a round bottomed flask $(60 \%$ of total volume of the flask) and performed the extraction for about 2 to 3 hours. Cool down the extract to room temperature and added $\mathrm{Na}_{2} \mathrm{SO}_{4}$ anhydrous to eliminate water. Filtered the extract and evaporated the solvent and collected the oils for further analysis.

\section{Determination of physicochemical proprieties Determination of acid value}

Put a Kabate larva oil $(10 \mathrm{~g})$ in a $250 \mathrm{~mL}$ flat-bottom round flask and added $25 \mathrm{~mL} 95 \%$ neutral alcohol $(95 \%$ alcohol that had been titrated with $0.1 \mathrm{~N} \mathrm{KOH}$ and turned to pink; using phenolphthalein indicator). The flasks were then fitted with condensate cooler and the mixture was heated to boil and strongly shaken out to dissolve its free fatty acids. The reaction product was cooled and subsequently titrated with a standardized 0.1 $\mathrm{N} \mathrm{KOH}$ solution using phenolphthalein indicator. The titration process was stopped when the pink color remains for the 30s. The acid value of the sample was calculated according to the following equation:

Acid value $(\mathrm{mg} / \mathrm{g}): \underline{\mathrm{KOH}}(\mathrm{mL}) \times \mathrm{N} \mathrm{KOH} \times 56.1$

$$
\text { Mass of the sample (g) }
$$

\section{Determination of saponification value}

A total of $1.0 \mathrm{~g}$ of Kabate larva oil was put in a $100 \mathrm{~mL}$ of flat-bottomed round flask. A total of $50 \mathrm{~mL}$ ethanolic $\mathrm{KOH}(4 \mathrm{~g} \mathrm{KOH} / 100 \mathrm{~mL} \mathrm{EtOH})$ was added and the flask was closed with a condensate cooler. The mixture was boiled for 30 minutes, cooled and added a few drops of phenolphthalein 
indicator. The solution was then titrated with a $0.5 \mathrm{~N}$ $\mathrm{HCl}$ standard solution. The titration was also performed to the blank solution. The saponification value was calculated by the following formula:

$$
\underset{(\mathrm{mg} / \mathrm{g})}{\text { Saponification value }}: \frac{\mathrm{V} \mathrm{HCl}(\mathrm{mL}) \times \mathrm{N} \mathrm{KOH} \times 56.1}{\text { Mass of the sample }(\mathrm{g})}
$$

where $\mathrm{V}$ is the volume of $\mathrm{HCl}$ used for titration and calculated by subtracting the total volume needed for titration of the blank solution and the sample ( $\mathrm{V} \mathrm{HCl}$ for blank - sample).

\section{Determination of peroxide number}

Peroxide number was determined by put $0.5 \mathrm{~g}$ of Kabate larva oil in a closed Erlenmeyer and added $30 \mathrm{~mL}$ glacial acetic acid-chloroform solution mixture (3:2). The mixture was then shaken well and added with saturated $\mathrm{KI}$ solution $(0.5 \mathrm{~mL})$ and after $1 \mathrm{~min}$. was added with $30 \mathrm{~mL}$ distilled water. The solution was then titrated with sodium thiosulfate $0.1 \mathrm{~N}$ until it turns into a pale yellow solution. To this solution, $0.5 \mathrm{~mL} 1 \%$ starch solution was added and titration continued until blue color disappear. Peroxide number was calculated by the following equation:

Peroxide number : $\mathrm{V} \mathrm{Na}_{2} \mathrm{~S}_{2} \mathrm{O}_{3}(\mathrm{~mL}) \times \mathrm{N} \mathrm{Na}_{2} \mathrm{~S}_{2} \mathrm{O}_{3} \times 1000$ (meg/kg) Mass of the sample $(\mathrm{g})$

\section{Determination of iodine number}

Kabate larva oil sample $(0.5 \mathrm{~g})$ was put in a closed Erlenmeyer and added with chloroform $(10 \mathrm{~mL})$ and $25 \mathrm{~mL}$ of iodine-bromide reagents. The mixture was shaken and placed in a dark place for 30 minutes. To the mixture was added $10 \mathrm{~mL}$ $15 \% \mathrm{KI}$ solution and $50 \mathrm{~mL}$ hot distilled water. The mixture was then titrated with sodium thiosulfate solution $\left(\mathrm{Na}_{2} \mathrm{~S}_{2} \mathrm{O}_{3} 0.1 \mathrm{~N}\right)$ until it turns to a pale yellow solution. To the solution was added $2 \mathrm{~mL}$ of starch solution and the titration was continued until the blue color disappeared. The blank solution was prepared by mixing $25 \mathrm{~mL}$ iodine-bromide reagent with $10 \mathrm{~mL} \mathrm{KI} \mathrm{15 \% .} \mathrm{This} \mathrm{solution} \mathrm{was} \mathrm{diluted} \mathrm{with}$ $100 \mathrm{~mL}$ of hot distilled water before being titrated with sodium thiosulfate solution. lodine number was calculated based on the following equation:

lodine number : $\quad \mathrm{V} \mathrm{Na}_{2} \mathrm{~S}_{2} \mathrm{O}_{3}(\mathrm{~mL}) \times \mathrm{N} \mathrm{Na}_{2} \mathrm{~S}_{2} \mathrm{O}_{3} \times 12.691$ Mass of the sample $(\mathrm{g})$ where $\mathrm{V} \mathrm{Na}_{2} \mathrm{SO}_{3}$ is a volume needed for titration and calculated by subtracting the total volume needed for titration the blank solution and the sample $\left(\mathrm{V} \mathrm{Na}_{2} \mathrm{~S}_{2} \mathrm{O}_{3}\right.$ for blank - sample).

\section{Determination of specific gravity}

Determination of the specific gravity of the Kabate larva oil was carried out according to the procedure mentioned in ASTM D 1298.

\section{Determination of kinematic viscosity}

The kinematic viscosity of Kabate larva oil was determined based on the procedures in ASTM D 445.

\section{Determination of fatty acid using GC-MS}

Conversion of fatty acids into its derivatives such as fatty acid ethyl ester is required so that it can be measured by Gas Chromatography-Mass Spectrometer (GC-MS) analysis. Kabate larva oil $(25 \mathrm{~g})$ and $50 \mathrm{~mL}$ of methanol was introduced into a flask that was equipped with a magnetic stirrer. To the mixture was added $2 \mathrm{ml}$ of $16 \%$ sodium methoxide (b/v) solution. The mixture was then stirred for $45 \mathrm{~min}$. and monitored by Thin Layer Chromatography. After the completion of the reaction, the solvent was evaporated and the residue was dissolved in $50 \mathrm{~mL}$ petroleum ether, poured into separating funnel and washed with water until reach neutral $\mathrm{pH}$. The organic layer was dried with anhydrous $\mathrm{Na}_{2} \mathrm{SO}_{4}$ and then the filtrate was evaporated. The residue was collected and analyzed by Gas Chromatography-Mass Spectrometer.

\section{RESULTS AND DISCUSSION}

Kabate larva oil can be extracted from its larva using Soxhlet extractor and n-hexane as a solvent. Kabate larva oil afforded as viscous yellow liquid as seen in Fig. 2 with a yield of $51 \%$.

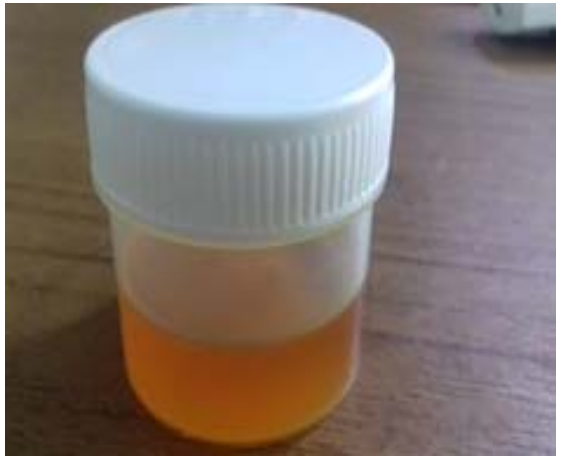

Fig. 2. Kabate larva oil 
The physical properties of Kabate larva oil were presented in Table 1.The physical propertiec of Kabate larva oil such as kinematic viscosities and specific gravity were determined according to the standard procedure (ASTM D 445 and 1298). Meanwhile, the chemical properties i.e. acid value, saponification value, peroxide numbers and iodine numbers were determined by titrimetric analysis.

Table 1: Physicochemical properties of Kabate larva oil

\begin{tabular}{ll}
\hline Parameters & Value \\
\hline Acid value & $1.58 \mathrm{mg} \mathrm{KOH} / \mathrm{gr}$ \\
Saponification value & $111.28 \mathrm{mg} \mathrm{KOH} / \mathrm{gr}$ \\
Peroxide number & $2.1554 \mathrm{meg} / \mathrm{kg}$ \\
lodine number & 44.1426 \\
Specific gravity $\left(15^{\circ} \mathrm{C}\right)$ & $0.8159 \mathrm{gr} / \mathrm{mL}$ \\
Kinematic viscosity $\left(100{ }^{\circ} \mathrm{C}\right)$ & $40.57 \mathrm{~mm} / \mathrm{s}$ \\
\hline
\end{tabular}

Triglycerides, an ester of glycerol and fatty acids, are the main components in vegetable oils or animal fats, besides free fatty acids and other components. Triglycerides of a vegetable oil or animal fat bind to a particular fatty acid, saturated or unsaturated fatty acids, as an ester with glycerol. The composition of fatty acids can be determined using GC-MS but it required some preparation steps.

Fatty acids in a vegetable oil or animal fat have a very high boiling point. Hence, the fatty acids must be converted to fatty acid methyl esters so they can be analyzed using GC-MS. In this work, the composition of fatty acids in the Kabate larva oil may be determined by GC-MS as Fatty Acid Methyl Ester (FAME). Conversion of triglycerides from Kabate larva oil into their fatty acid methyl esters (FAME) was carried out through transesterification reactions.

Transesterification of Kabate larva oil was performed to convert fatty acids which bound to triglyceride ester to methyl ester. The transesterification reaction of Kabate larva oil was carried out using methanol and sodium methoxide catalyst at room temperature for 3.5 hours. The transesterification reaction of triglyceride into its FAME using methanol and the alkaline catalyst is called methanolysis. In this work, $16 \%$ sodium methoxide solution $(b / v)$ in methanol was used as the basic catalyst. The sodium methoxide solution was prepared by reacting the sodium metal with absolute methanol at room temperature through an oxidation-reduction reaction. The transesterification reaction of the Kabate larva oil produced methyl ester as a light yellow liquid in the $\mathrm{n}$-hexane phase. Meanwhile, the glycerol as side products of transesterification reaction was separated in the polar phase.

The Kabate larva oil methanolysis is preceded by the attack of methoxide ions on the carbonyl carbon atom of triglycerides and through the addition-elimination steps, it can be produced a methyl-methyl ester and glyceride ions. The methoxide ion can be recovered from the reaction of glyceride ion with methanol. This reaction could take place in reverse, so in order to obtain methyl ester products, it requires an excess of methanol. The mechanism of addition-elimination reaction of the methoxide ion to the carbonyl group of triglycerides may occur as in Figure 3.

The transesterification reaction product which was a mixture of methyl ester was then analyzed using GC-MS. The chromatogram and mass spectra were presented in Fig. 4, Fig. $5 \mathrm{a}$ and Fig. 5b. Chromatogram of the transesterification products of Kabate larva oil (Fig. 4) showed 2 peaks at a retention time $\left(t_{R}\right)$ of 33.91 and 37.24 min. with a percentage value of 43.57 and $56.43 \%$ respectively.

The mass spectra of Fig. $5 \mathrm{a}$ showed that the peak with a retention time of $33.91 \mathrm{~min}$ was methyl palmitate compound with the appearance of molecular ions $\left(\mathrm{M}^{+}\right)$at $\mathrm{m} / \mathrm{z}=270$, which is corresponded to the molecular weight of methyl palmitate. Meanwhile, the mass spectra of the peak with $t_{R} 37.24$ min (Fig. 5b) showed a base peak at $\mathrm{m} / \mathrm{z}=55$ and peak at $\mathrm{m} / \mathrm{z}=264$. Even the result did not show any molecular ion $\left(\mathrm{M}^{+}\right)$at $\mathrm{m} / \mathrm{z}=296$, this mass spectrum has $96 \%$ similarity index (SI) with the data base indicate that the peak was methyl oleate. Fragments with $\mathrm{m} / \mathrm{z}=264$ are formed due to the release of a methanol molecule ion $(\mathrm{m} / \mathrm{z}=32)$. Fragments with the greatest abundance and stable at $\mathrm{m} / \mathrm{z}=55$ was a fragment with $\mathrm{CH}_{2} \mathrm{CHCO}$ structures. 


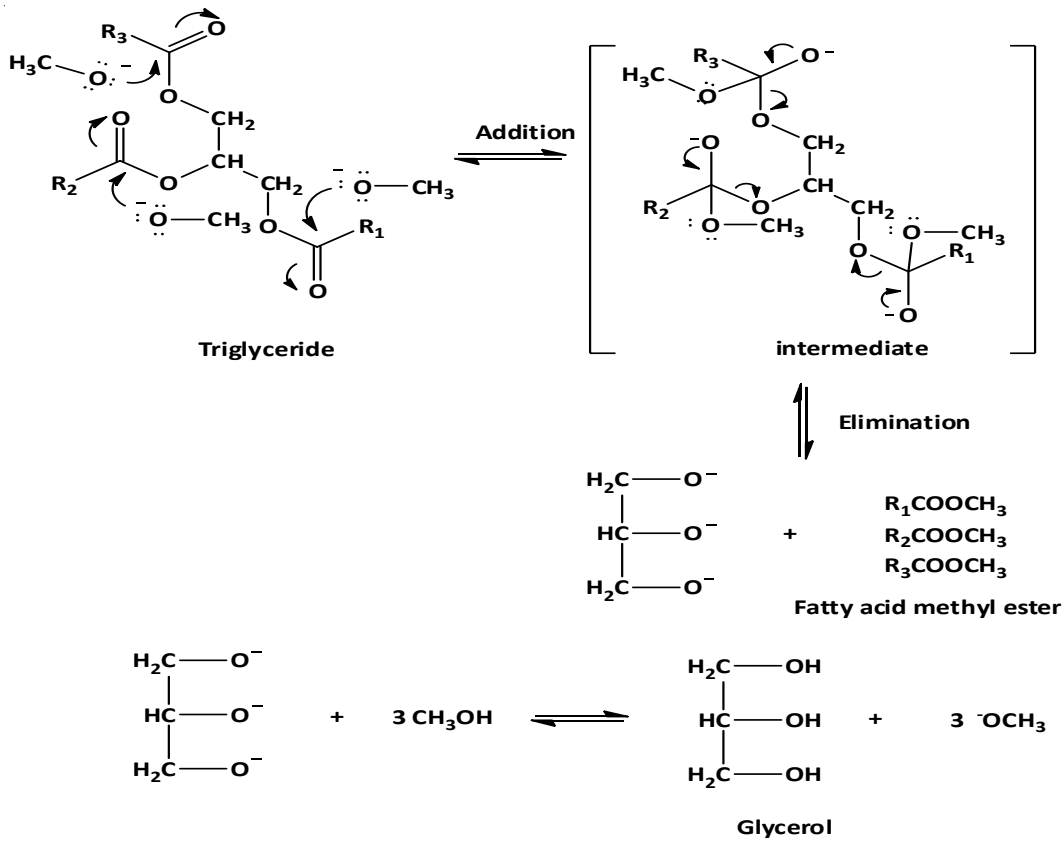

Fig. 3. Transesterification reaction mechanism of triglyceride

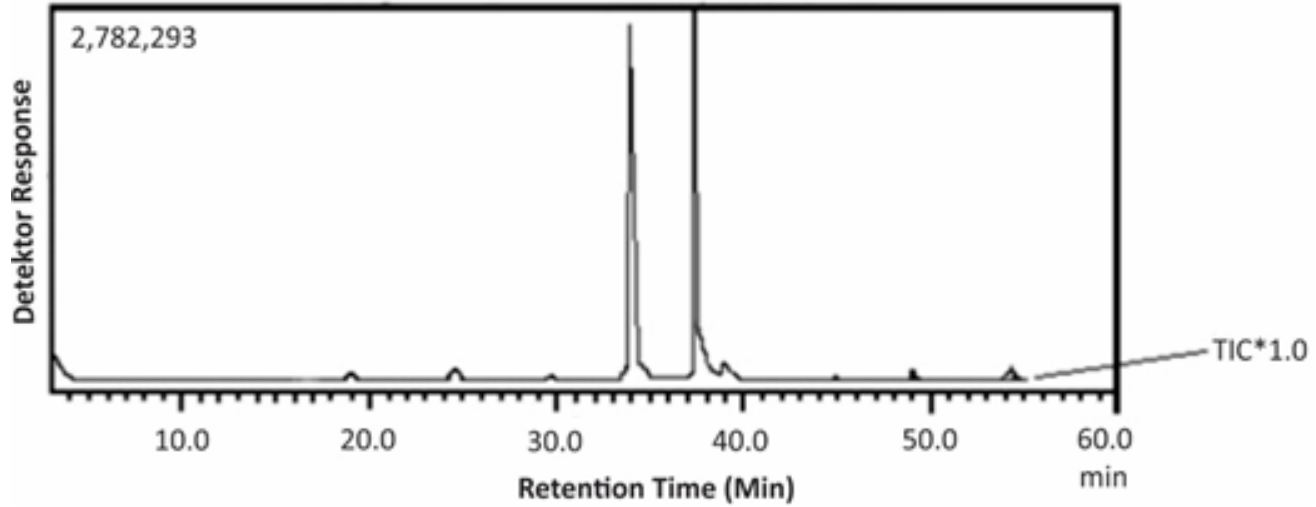

Fig. 4. Chromatogram of transesterification product of "Kabate" larva oil

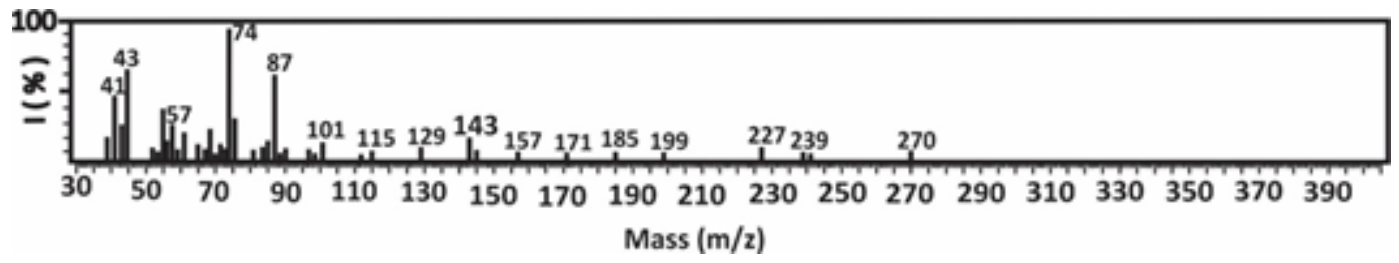

Fig. 5a. Mass spectra of peak at $t_{R} 33.91$ minutes

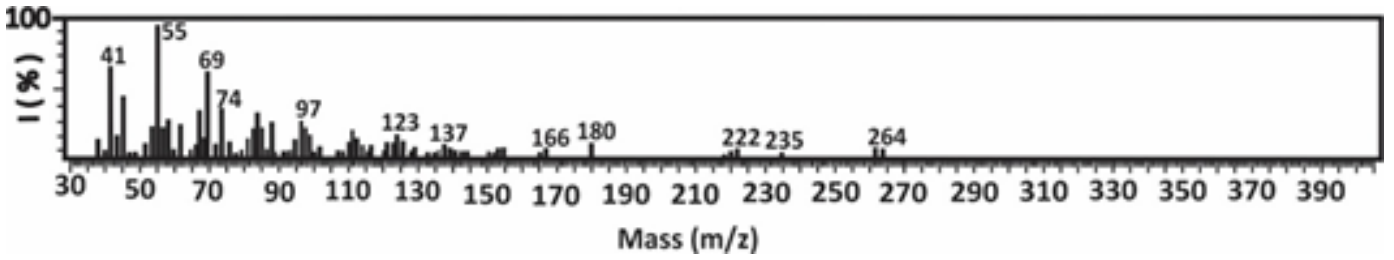

Fig. 5b. Mass spectra of peak at $t_{R} 37.24$ minutes 
Based on the GC-MS analysis, it can be concluded that the transesterification reaction of Kabate larva oils with methanol and alkaline catalysts produce methyl palmitate and methyl oleate. Thus, the fatty acids composition of the Kabate larva oil were palmitic acid and oleic acid with the percentage of 43.57 and $56.43 \%$ respectively.

\section{CONCLUSION}

1. Kabate larva oils were afforded in a viscous yellow liquid from an extract of Kabate larva by Soxhlet methods using $n$-hexane as a solvent with a yield of $51 \%$.

2. The physicochemical properties of Kabate larva oil such as acid value, saponification value, peroxide number, iodine number, kinematic viscosity $\left(100^{\circ} \mathrm{C}\right)$ and the specific gravity $\left(15^{\circ} \mathrm{C}\right)$ were $1.58 \mathrm{mg} \mathrm{KOH} / \mathrm{g} ; 111.28$ $\mathrm{mg} \mathrm{KOH} / \mathrm{g} ; 2.1554$ meg/kg; 44.1426; 0.8159 $\mathrm{g} / \mathrm{mL}$; and $40.57 \mathrm{~mm}^{2} / \mathrm{s}$ respectively.

3. The types of fatty acids contained in Kabate larva oil were found to be palmitic acid and oleic acid with percentage composition of 43.57 and $56.43 \%$ respectively.

\section{ACKNOWLEDGEMENT}

Authors showed gratitude to Ministry of Research, Technology, and Higher Education Indonesia for the financial support of this work through Hibah Penelitian Produk Terapan (PPT) T.A 2017.

\section{REFERENCES}

1. Nitbani, F.O.; Jumina, Siswanta, D.; Sholikhah, E.N., Int. J. Pharm. Sci. Rev. Res. 2015, 35 (1), 126-136.

2. Hierholzer, J.C; Kabara, J.J., J. Food Saf., 1972, 4, 1-12.

3. Chaibi, A.; Ababouch, L.; and Busta, F., J. Food Prot. 1996, 59(7), 716-722.

4. Langone, M.A.P.; Dee Abreu, M.E.; Rezende, M.D.C; Sant'anna, G.L.J.R., Appl. Biochem. Biotechnol. 2002, 98-100.

5. Ugbogu O.C.; Onyeagba R.A.; Chigbu O.A., Afr. J. Biotechnol. 2006, 5(11), 1045-1047.

6. Hedge, B.M., Journal Indian Academy of
Clinical Medicine, 2006, 7(1): 16-19.

7. Widiyarti G.; Hanafi M.; Soewarso W.P., Indo. J. Chem. 2009, 9(1), 99-106.

8. Nitbani, F.O.; Jumina, Siswanta, D.; Sholikhah, E.N.; and Fitriastuti, D., Orient. J. Chem., 2016, 32(6), 1-8.

9. Nitbani, F.O.; Jumina, Siswanta, D.; Sholikhah, E.N., Int. J. Pharm. Sci. Rev. Res. 2015, 39(1), 74-80.

10. Zhao, Y.; Liu J.; Deng L.; Wang, F.; Tan T., J. Mol. Catal. B: Enzym. 2011, 72, 157-162.

11. Wang, X.; Jina, Q.; Wang, T.; Huanga, J.; Wanga, X. J. Mol. Catal. B: Enzym. 2013, 97, 130-136. 